\title{
Studi Sistem Informasi Monitoring Pembelian Material (Studi Kasus: K5-Project IKPT Toyo)
}

\author{
Abdul Zain ${ }^{1, a}$ dan Hari Susanto ${ }^{1}$ \\ ${ }^{1}$ Sekolah Tinggi Teknologi Bontang, \\ J1. Ir. H. Juanda, No. 73, Tanjung Laut, Kota Bontang, Kalimantan Timur 75321, Indonesia \\ ${ }^{\mathrm{a} E m a i l ~: ~ j a i n b t g 2013 @ g m a i l . c o m ~}$
}

\begin{abstract}
Kaltim-5 Factory is the biggest plant for Ammonia and Urea in Indonesia. Construction of this plant was executed by Consortium IKPT-TOYO. Along the construction stage, procurement for materials were absolutely needed, and Procurement Department IKPT-TOYO has responsibility to handle materials procures. System that currently used is still using Microsoft Excel by manual input for each steps beginning from inquiry stage, getting vendor quotation until PO issued. This method still has some problems occurred such as uncontrolled stock and material requisition, also inquiry sheet which can be easily lost. In order to support the completion of K5-Project that needs more materials, therefore it needs a system that can ease and also improve the work of Procurement Department. Based on this background, research study to resolve this problem is held. This system gives status information and it is integrated to the each control step smoothly. System development used on this program is SDLC with Waterfall model. Moreover, testing methods is using Black Box system. The design of this monitoring information system describes a work order application by using PHP Macromedia Dreamweaver 8, AppServ 2.10.2 as web server and MySQL as database. Having testing the application, the result of this study shows that the application is able to improve the data processing of material procurement with minimum of error and high accuracy.
\end{abstract}

Keywords: Materials, Monitoring, and Procures.

Abstrak--Pabrik Kaltim-5 merupakan pabrik penghasil ammonia dan urea terbesar di Indonesia. Pembangunan pabrik tersebut dikelola oleh IKPT TOYO. Selama masa pembangunan pabrik, tentu saja pabrik membutuhkan material-material pendukung. Hal tersebut menuntut Procurement Departement bertanggungjawab untuk mengelola pembelian material. Saat ini sistem yang digunakan dalam manajemen kegiatan pembelian material meliputi pengajuan request sampai dengan pembuatan PO masih menggunakan cara sederhana yaitu dengan mengajukan request terlebih dahulu kemudian diinputkan ke software Microsoft Excel setelah itu tim RUP menunggu quotation dari vendor dan selanjutnya proses pembuatan PO. Hal ini menyebabkan proses pengajuan material sering mengalami beberapa kendala diantaranya adalah material yang direquest ternyata masih ada stok di gudang, material yang telah dibeli tidak tercatat di gudang dan form pengajuan material hilang.
Guna menunjang penyelesaian pembangunan pabrik Kaltim-5 yang membutuhkan banyak material, maka diperlukan suatu sistem yang mempermudah dan mempersingkat pekerjaan di Procurement Department. Tujuan Penelitian yakni sistem ini dapat memberikan informasi status pembelian material dan sistem saling terintegrasi sehingga bagian pembelian dapat segera memproses pengadaan barang. Metode pengembangan sistem yang peneliti gunakan dalam penelitian ini adalah metode SDLC model waterfall. Sedangkan metode pengujian sistem yang digunakan adalah blackbox. Perancangan sistem informasi monitoring pembelian material menggambarkan aplikasi pengajuan pekerjaan yang memanfaatkan bahasa pemprograman PHP dengan menggunakan komponen tambahan aplikasi Macromedia Dreamweaver 8, AppServ 2.10.2 sebagai webserver dan database MySQL sebagai media penyimpanan data. Hasil dari penelitian ini adalah sistem informasi yang dapat meningkatkan kinerja dalam pengolahan data pembelian material, menghasilkan data dan informasi yang akurat, cepat dan meminimalisir kesalahan.

Kata kunci : Material, Monitoring, dan Pembelian.

\section{Pendahuluan}

Proses pembangunan pabrik Kaltim-5 di PT. Pupuk Kaltim oleh Inti Karya Persada Teknik (IKPT) dan Global TOYO yang selanjutnya disingkat menjadi IKPT TOYO, melakukan transaksi pembelian material pabrik. Material tersebut dapat berupa pipa, valve, elbow dan sebagainya yang berkaitan dengan alat kebutuhan pabrik. Pembelian material selanjutnya diproses oleh Procurement Department. Bagian dari Procurement Department terdapat satu tim yang disebut Request for Urgent Procurement (RUP) yang bertugas untuk membeli material yang dibutuhkan oleh perusahaan.

Beberapa kegiatan Procurement dalam proses pembelian material dimulai dari permintaan engineer untuk kebutuhan material sampai dengan material tersedia di site. Selanjutnya RUP meminta persetujuan 
dari manajemen yang berakhir dengan membuat Purchase Order (PO) sebagai dasar perjanjian yang harus disepakati antara kontraktor dan vendor.

Dari proses kegiatan dari tim RUP Procurement tersebut, ada beberapa kendala dalam mengontrol material, yaitu kesulitan dalam memonitor material yang masuk dari vendor dalam jumlah banyak dan bisa secara langsung disortir ke masing-masing folder department. Sering terjadi kesalahan pembacaan status perincian data, dengan kata lain pembacaan status data dari department tersebut tidak sesuai dengan aktualnya.

Peneliti memiliki beberapa studi penelitian terdahulu yang dapat menjadi bahan referensi antara lain :(1). Dodi Wahyugi dengan judul Pengembangan Sistem Informasi Pelaporan Monitoring dan Evaluasi Badan Perencanaan Pembangunan Daerah Kabupaten Bengkulu Utara Berbasis Web [1]. Penelitian ini membuat pengembangan sistem informasi monitoring dan evaluasi dari sistem manual menjadi terkomputerisasi dengan menggunakan PHP dan MySql serta pemanfaatan internet sebagai jaringan komunikasi. Penelitian ini memaksimalkan akurasi laporan dan sebagai sarana akses informasi kepada masyarakat terhadap laporan monitoring dan evaluasi pembangunan daerah. (2). Gentisya Tri Mardiani dengan judul Sistem Monitoring Data Aset dan Inventaris PT. Telkom Cianjur Berbasis Web [2]. Penelitian yang dilakukan menjalankan proses monitoring terhadap data aset dan data distribusi perangkat kepada karyawan dapat dilakukan sehingga kejelasan informasi dan kesesuaian antara sumber data dan bukti fisik di lapangan dapat terjaga.

Landasan teori berhubungan dengan penelitian ini antara lain Monitoring. Menurut Peraturan Pemerintah Nomor 39 Tahun 2006 [3], disebutkan bahwa monitoring merupakan suatu kegiatan mengamati secara seksama suatu keadaan atau kondisi, dengan tujuan agar semua data masukan atau informasi yang diperoleh dari hasil pengamatan tersebut dapat menjadi landasan dalam mengambil keputusan tindakan selanjutnya yang diperlukan.

\section{Metode Penelitian}

\section{A. Metode Penelitian}

Penelitian dilakukan pada bulan Oktober 2015 hingga Januari 2016 di Departemen Procurement K5Project IKPT TOYO yang berlokasi di area pabrik PT. Pupuk Kaltim. Data yang digunakan dalam penelitian adalah informasi pengolahan data pembelian material di Departemen Procurement.

Metode penelitian ini mencakup dua hal yaitu metode pengumpulan data dan metode pengembangan sistem.

a. Metode Pengumpulan Data

Metode pengumpulan data yang dilakukan peneliti meliputi observasi dan studi pustaka.

1) Observasi

Metode ini dilakukan berupa pengamatan secara langsung terhadap proses pembelian material di K5Project IKPT TOYO pada bagian procurement, dengan tujuan untuk mendapatkan data-data yang diperlukan untuk penulisan penelitian ini.

2) Studi Pustaka

Metode ini dilakukan dengan cara memahami dan mempelajari permasalahan yang berkaitan dengan perancangan sistem informasi monitoring pembelian material, kemudian mencari solusinya dari buku-buku, jurnal ilmiah, dan literatur yang berkaitan dengan penelitian ini.

b. Metode Pengembangan Sistem

Metode pengembangan sistem yang dilakukan peneliti dalam pembuatan penelitian ialah sebagai berikut:

1) Analisis

Mempelajari dan menganalisis sistem informasi yang sedang berjalan, mengetahui sebab dan kendala yang dihadapi saat penelitian dilakukan di K5-Project IKPT TOYO.

2) Perancangan

Perancangan sistem informasi dibuat dengan merancang output, input, struktur file, program dan prosedur yang diperlukan menggunakan perangkat lunak yang tersedia.

3) Pengujian

Membangun dan menginstalasi perangkat lunak yang diperlukan untuk mendukung sistem 
serta melakukan testing secara akurat menggunakan pengujian blackbox.

4) Implementasi

Implementasi sistem baru yang beralih dari sistem lama untuk lebih mempermudah pengguna dalam kegiatan pembelian material.

\section{B. Proses Penelitian}

Proses pertama, peneliti melakukan studi literatur yang berkaitan dengan mekanisme pembelian material, hal tersebut akan digunakan peneliti dalam proses penulisan dan pengembangan dalam rancangan sistem.

Selanjutnya proses kedua adalah mengumpulkan dan menganalisis dokumen-dokumen yang digunakan dalam kegiatan pengajuan RUP. Pada tahapan ini peneliti melakukan proses wawancara dengan pihak Procurement Department guna memperoleh data kelemahan terhadap metode kerja yang digunakan dalam kegiatan pembelian material tersebut.

Tahapan ketiga adalah mengkaji ulang terhadap literature dan hasil wawancara yang telah diperoleh, hal tersebut bertujuan untuk membangun dan memberikan gambaran sebuah rancangan sistem yang dapat membantu, mempermudah kegiatan pengajuan RUP.

Didalam perancangan sistem pembelian material ini peneliti mengacu pada metode System Development Life Cycle (SDLC) Model Waterfall yang berfungsi sebagai metode pengembangan dalam hal merancang Sistem Informasi Monitoring Pembelian Material seperti pada gambar 1 berikut.

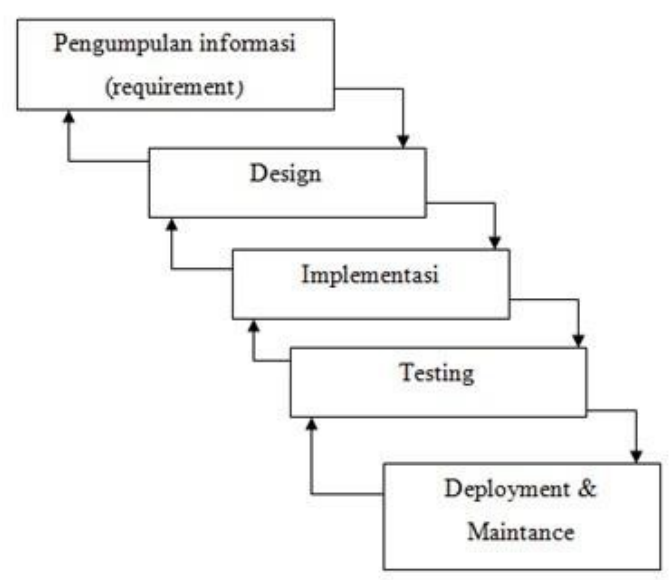

Gambar1. SDLC Model Waterfall [2]

\section{Perancangan Sistem}

Menurut [4] tujuan utama perancangan sistem adalah;

1. Untuk memenuhi kebutuhan para pemakai sistem.

2. Untuk memberikan gambaran yang jelas dan rancang bangun yang lengkap kepada programmer.

Agar lebih mudah untuk memahami maka peneliti membuat sebuah perancangan sistem dalam laporan penelitian ini. Metode perancangan sistem yang peneliti lakukan didalam penyusunan laporan penelitian ini terdiri dari Flow Of Document (FOD), ContextDiagram, Data Flow Diagram (DFD) dan Entitiy Relationship Diagram (ERD).

a. Flow Of Document (FOD)

Berikut ini adalah tampilan Flow of Document (FOD) pada Sistem Informasi Monitoring Pembelian Material di K5-Project IKPT TOYO, seperti pada gambar 2 .

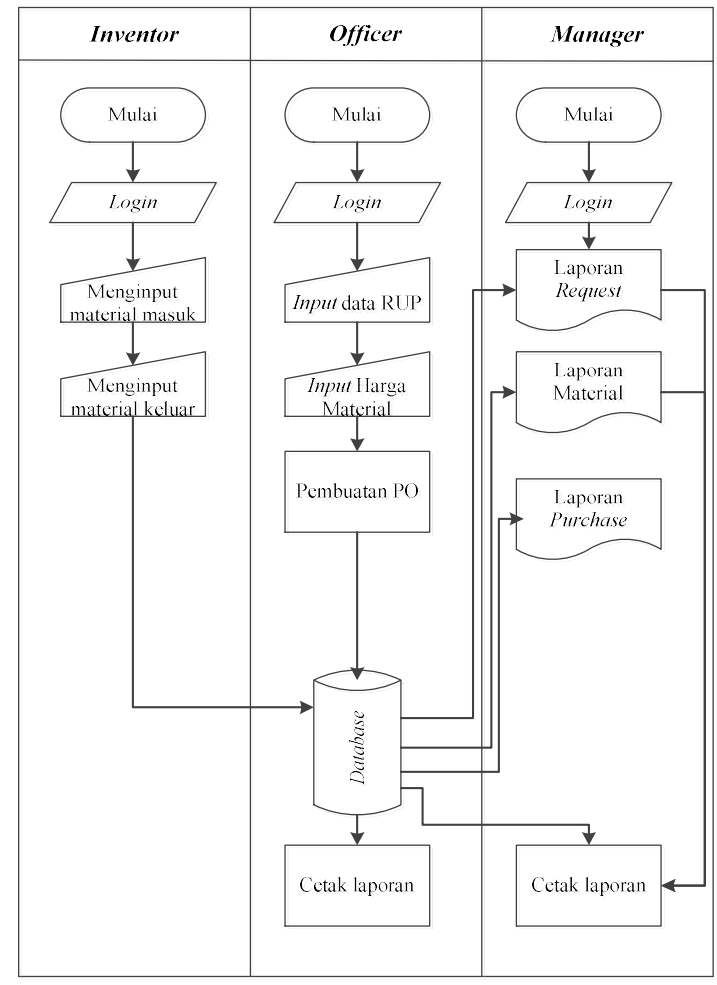

Gambar 2.Tampilan Flow of Document (FOD) Sistem Informasi Monitoring Pembelian Material

\section{b. Context Diagram}

Context Diagram merupakan diagram yang digunakan untuk struktur analisis. Pendekatan terstruktur ini peneliti mencoba untuk menggambarkan system secara garis besar atau keseluruhan. Context 
Diagram Tampilan Sistem Informasi Monitoring Pembelian Material di K5-Project IKPT TOYO dapat dilihat pada gambar 3 berikut.

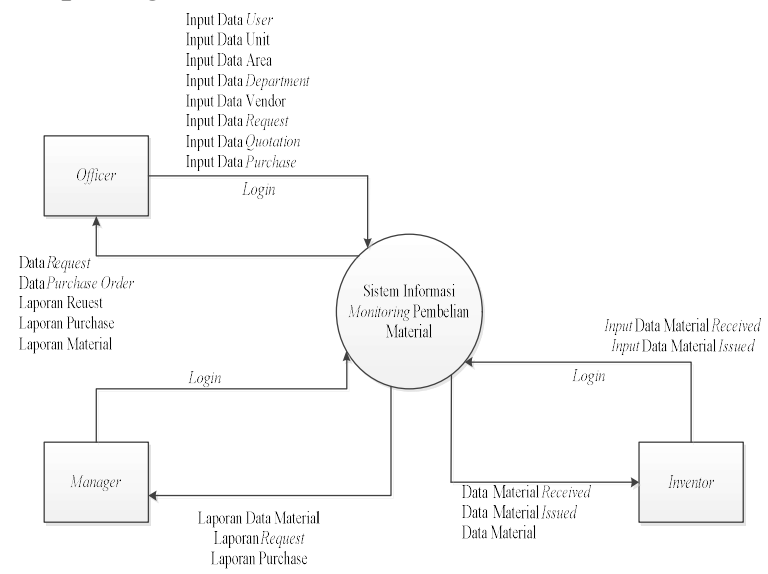

Gambar 3. Tampilan Context Diagram Sistem Informasi Monitoring Pembelian Material

\section{c. Data Flow Diagram (DFD)}

Data Flow Diagram (DFD) yang diusulkan merupakan representasi grafik dari sebuah sistem monitoring pembelian material yang menggambarkan komponen-komponen sebuah aliran data yang menghubungkan proses-proses sistem. DFD dalam perancangan. Tampilan Sistem Informasi Monitoring Pembelian Material dapat dilihat pada gambar 4 berikut.

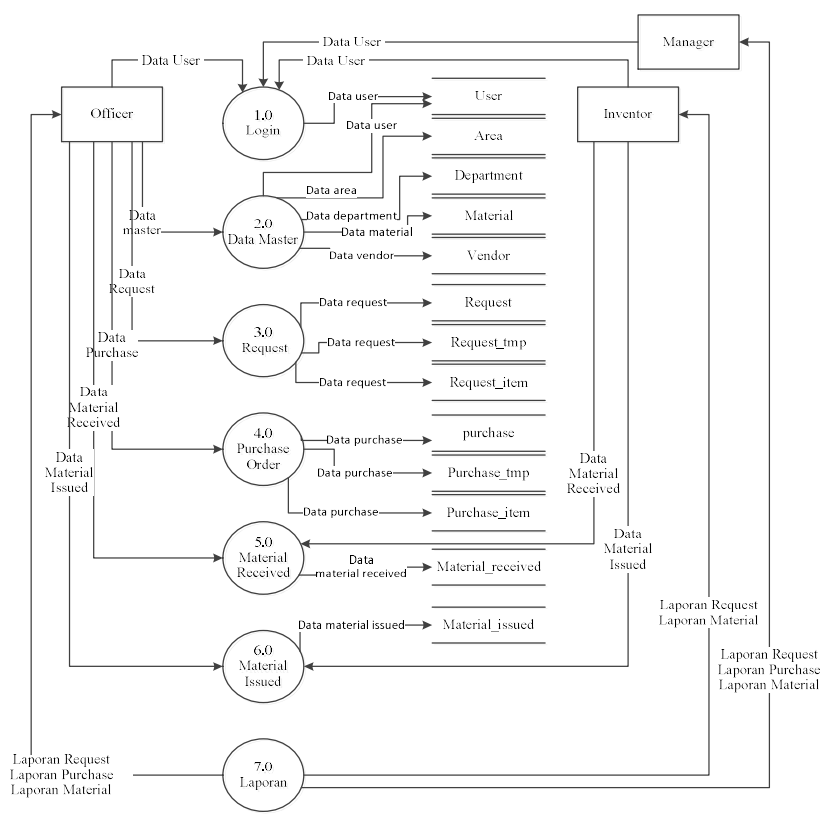

Gambar 4. Tampilan DFD Level 0 Sistem Informasi Monitoring Pembelian Material d. Entity Relationship Diagram(ERD)

Entiyi Relationship Diagram(ERD) menggambarkan keterkaitan antar tabel beserta dengan fielf-field di dalamnya pada suatu database sistem. Tampilan ERD tersebut dapat dilihat pada gambar 5 berikut.

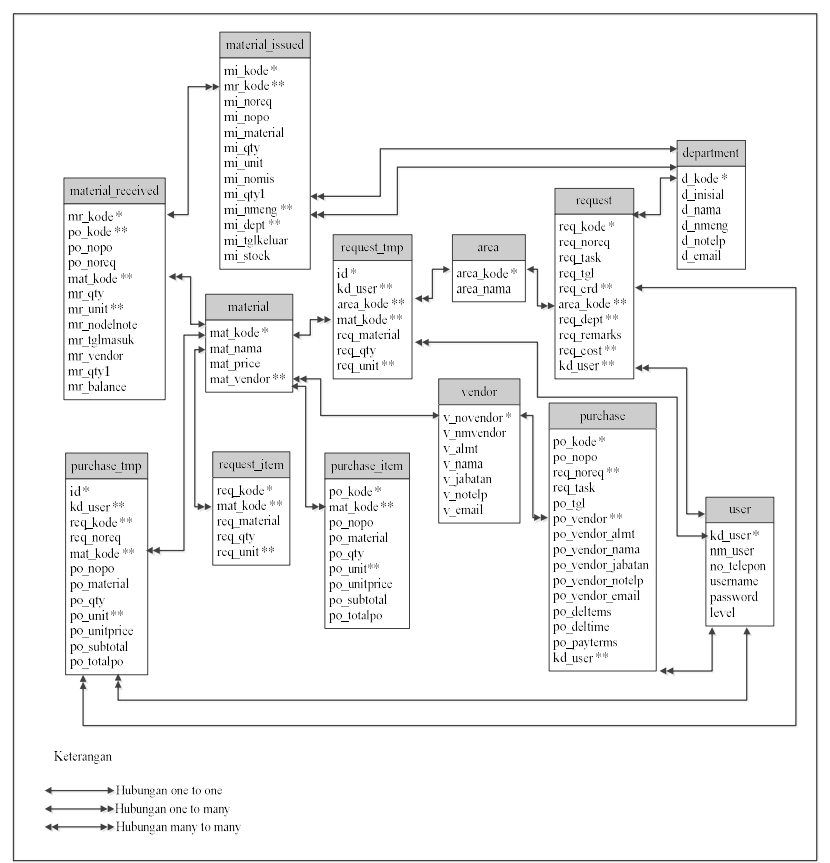

Gambar 5. Tampilan ERD Sistem Informasi Monitoring Pembelian Material

\section{Hasil dan Pembahasan}

\section{A. Hasil Penelitian}

Hasil penelitian merupakan proses dan tahapan dimana system siap dioperasikan pada keadaan yang sebenarnya, maka melalui proses ini akan diketahui apakah sistem yang dibuat benar-benar dapat menghasilkan tujuan yang diinginkan. Hasil penelitian dalam perancangan Sistem Informasi Monitoring Pembelian Material, berdasarkan hasil analisa permasalahan yang penulis peroleh di K5-Project IKPT TOYO dan menuangkannya ke sebuah bahasa pemograman PHP sehingga tercipta sebuah system dengan kapabilitas yang dapat membantu proses pengajuan RUP di Procurement Department. 
a. Tampilan Antar Muka

\section{Login}

Form login digunakan untuk sarana keamanan dan pengelompokan hak akses terhadap penggunaan system dengan menginputkan username, password dan level. Berikutt ampilan form login seperti pada gambar 6.

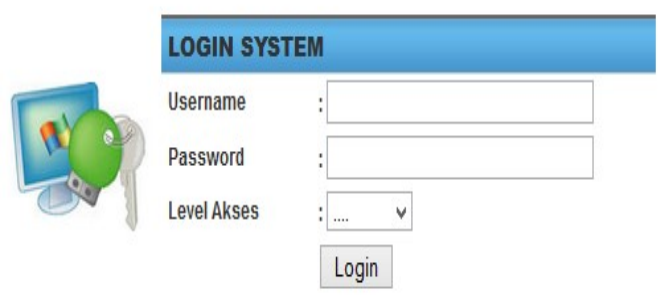

Gambar 6. Form login

\section{Menu Utama}

Menu utama merupakan menu yang tampil ketika pengguna sukses melakukan login ke sistem, didalam menu utama terdapat beberapa sub menu yang memiliki fungsi berbeda-beda dalam pengolahan dan pemrosesan data hingga menjadi sebuah informasi. Berikut tampilan menu utama seperti pada gambar 7 .

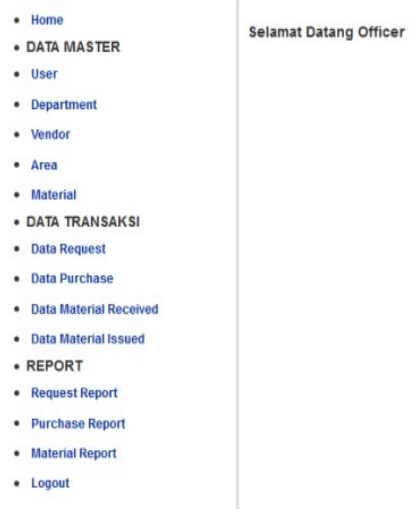

Gambar 7. Tampilan Menu utama

\section{Transaksi Request}

Transaksi request digunakan untuk menampilkan data material yang dibutuhkan oleh engineer. Berikut tampilanTransaksi Request seperti pada gambar 8 .

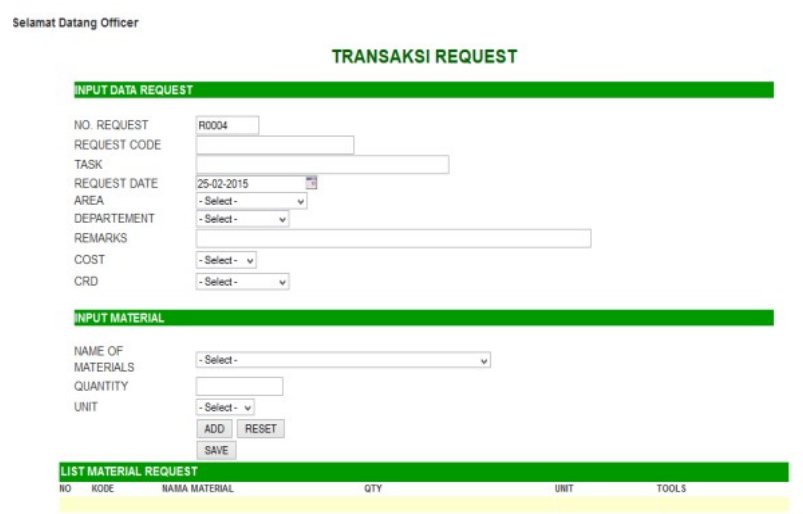

Gambar 8. Tampilan Transaksi Request

\section{Transaksi Purchase Order}

Transaksi purchase order berfungsi sebagai media penginputan data request yang dibutuhkan, pada form transaksi purchase order ini pengguna diharuskan memasukan data secara lengkap terkait request material yang diajukan. Berikut tampilan transaksi purchase order seperti pada gambar 9 .

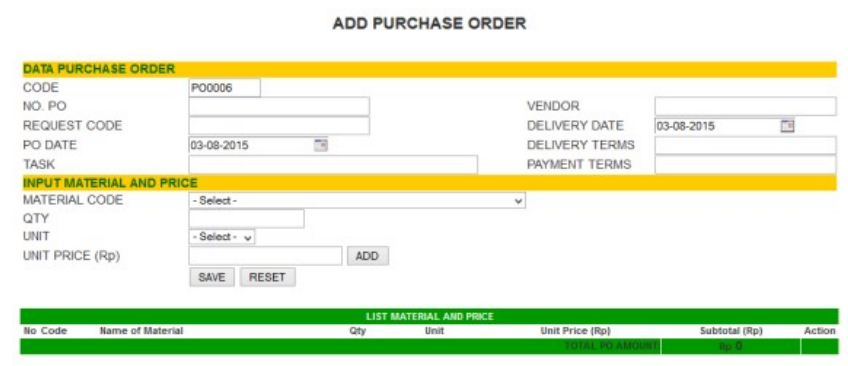

Gambar 9. Tampilan Transaksi Purchase Order

\section{Transaksi Material Received}

Transaksi material received berfungsi sebagai media penginputan data material yang diterima inventor sesuai dengan data request dan purchase order. Berikut tampilan transaksi material received seperti pada gambar 10.

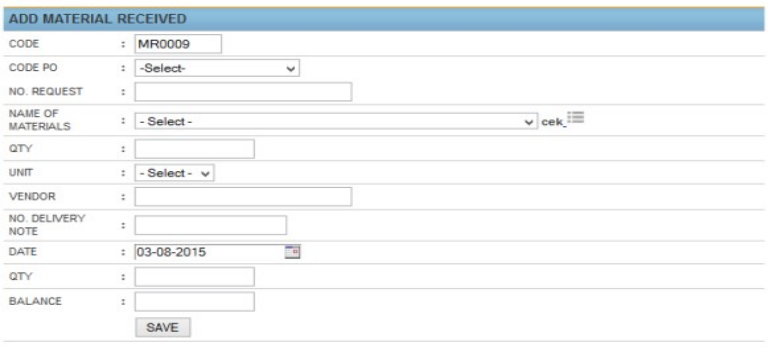

Gambar 10.Tampilan Transaksi Material Received 


\section{Transaksi Material Issued}

Transaksi material issued berfungsi sebagai media penginputan data material yang diterima inventor sesuai dengan data material received. Berikut tampilan transaksi material issued seperti pada gambar 11.

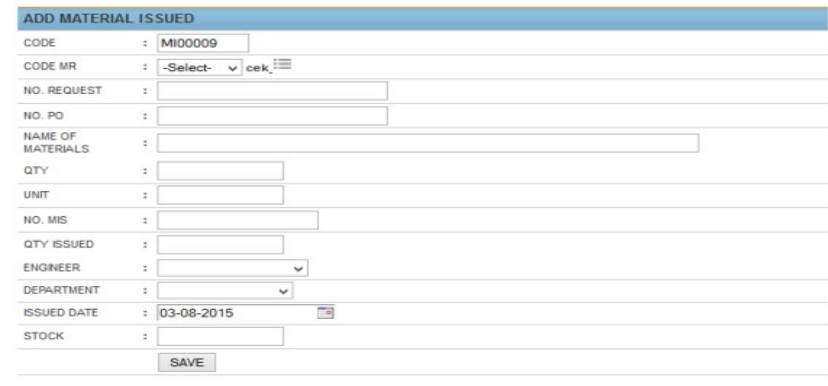

Gambar 11. Tampilan Transaksi Material Issued

\section{Laporan Request}

Laporan request merupakan output data inputan transaksi request, laporan tersebut dapat dicetak dan selanjutnya dijadikan sebagai bahan verifikasi data bagi RUP team dalam mengambil keputusan terhadap pembelian request tersebut. Berikut tampilan laporan request yang telah di export excel seperti pada gambar 12.

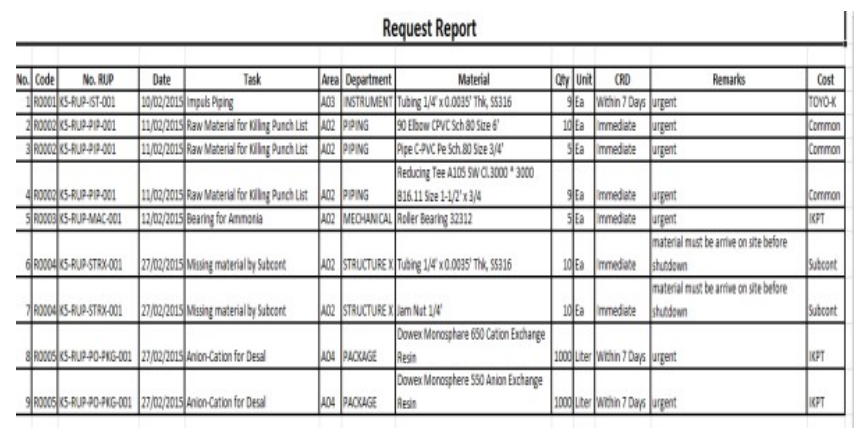

Gambar 12. Tampilan Laporan Request

\section{Laporan Purchase Order}

Laporan purchase order merupakan output data dari proses penginputan request, laporan purchase order merupakan perhitungan biaya pembelian material dari data requestdan data harga yang diperoleh dari quotation vendor. Berikut tampilan laporan purchase order yang telah di export to excel seperti pada gambar 13.
Purchase Report

\begin{tabular}{|c|c|c|c|c|c|c|c|c|c|c|}
\hline \multicolumn{11}{|c|}{ Purchase Report } \\
\hline No, code & No.PO & Date & Vendor & Material & \begin{tabular}{|l|l|l|}
$Q$ Qty & Unit \\
\end{tabular} & Unit Price & Sub Total & \begin{tabular}{|l|l|} 
Deliver Time| & \\
\end{tabular} & edelliver Term. & 15 Payment Tems \\
\hline 1.0000 & 15 KS-RUP-PO-PKG-001 & 28/02/2015 & |FT. Padi hijub Uuana & $\begin{array}{l}\text { Dowex Monosphare 650 Cation } \\
\text { Exchange Resin }\end{array}$ & 1000 liter & 61500 & 61500000 & 05/303/2015: & 15 For Bontangrg & Cass \\
\hline 20000 & 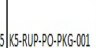 & 28020201015 & 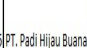 & $\begin{array}{l}\text { Dowex Monosphere } 550 \text { Anion Exctangege } \\
\text { Resin }\end{array}$ & 1000 Weter & 125000 & $\mid 128000000$ & $05[0 / 2 / 201015:$ & 15 For Bonthrs: & СКБН \\
\hline 10000 & 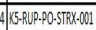 & $28 / 02201215$ & QV. Rasi Gemilang & 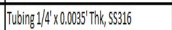 & 10 ea & 85000 & 850000 & $28002 / 20151$ & 15 Fanco bontant & $3000 y / 5$ \\
\hline 40000 & 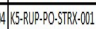 & 28020201015 & QV. RasiG Gemilang & Igm Nut1/4' & 10.-Seledt & 114000 & 1140000 & 2800202015 & 15 Franc Bontant & 18009/5 \\
\hline 50000 & 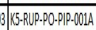 & $26 / 02 / 2015$ & (QV. P. Putra Mandiri & 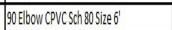 & $10 \mid E_{3}$ & 550000 & 5500000 & $27 / 02 / 2015$ & 15 Finno Bontant & 1800y/5 \\
\hline 510000 & 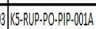 & 260/02/2015 & (WV, Putra Mandiri & 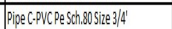 & $\sqrt{53}$ & 598000 & 299000 & $27 / 02 / 2015$ & 15 Frno Bontant & $30090 / 5$ \\
\hline$\sqrt{10000}$ & 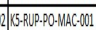 & $25002 / 2015$ & 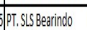 & Redlergegring 23:12 & 5 & 676000 & 338000 & $26602 / 2015$ & 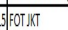 & Cash \\
\hline poovo & 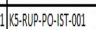 & $23 / 02 / 2015$ & SW, Rasi Gemilang & 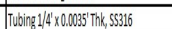 & 秘 & 80000 & 755000 & $2 / 0 / 2 / 20151$ & 15Frano Bontang & 30 Oays \\
\hline
\end{tabular}

Gambar 13.Tampilan Laporan Purchase Order

\section{Laporan Material}

Laporan material merupakan output dari proses penginputan data material received dan material issued, laporan material menampilkan stok material yang ada di warehouse. Berikut tampilan laporan material yang telah di export to excel seperti pada gambar 14.

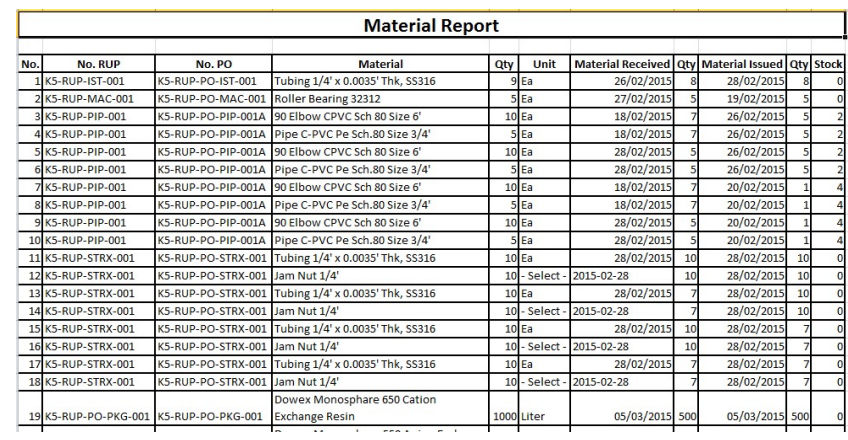

Gambar 14. Tampilan Laporan Material

\section{Kesimpulan dan Saran}

\section{A. Kesimpulan}

1. Sistem Informasi ini sangat membantu tim RUP dalam pembelian material, dan dalam mendapatkan informasi material, sistem ini menjadi alat bantu bagi user dalam proses pengolahan data pembelian dan pengadaan.

2. Pekerjaan user akan lebih efektif dengan dibantuoleh sistem ini, semua data terkait pembelian material akan terdata dan memudahkan user saat akan melakukan pembelian material. 
B. Saran

Dalam pembuatan sistem informasi pembelian material dalam suatu proyek, masih banyak hal yang perlu dikembangkan, seperti :

1. Sistem informasi yang sudah dibangun ini kedepannya bias dikembangkan kearah sistem monitoring yang memungkinkan software mengirimkan pesan berupa email ataupun SMS gateway sehingga lebih memudahkan user dalam memonitor pembelian material.

2. Pengembangan untuk kemampuan system mengolah inventory guna mendeteksi potensial kekurangan dan kelebihan material terhadap kebutuhan proyek kedepannya bias dikembangkan.

3. Penambahan fitur Catalog Material untuk pengembangan kedepannya agar memudahkan user meng-unggah deskripsi material yang akan dibeli dan menghindarkan user dari kesalahan input spesifikasi material.

\section{Ucapan Terima Kasih}

Penulis mengucapkan banyak terima kasih atas bantuan pihak-pihak berikut:

a. Pimpinan PT. Pupuk Kaltim Tbk

b. Pimpinan Departemen Procurement K5-Project IKPT TOYO

\section{Daftar Pustaka}

[1] Wahyugi, Dodi. 2012. Pengembangan Sistem Informasi Pelaporan Monitoring dan Evaluasi Badan Perencanaan Pembangunan Daerah Kabupaten Bengkulu Utara Berbasis Web. Depok.

[2] Mardiani, Gentisya T. 2013. Sistem Monitoring Data Aset dan Inventaris PT Telkom Cianjur Berbasis Web. Jurnal Ilmiah Komputer dan Infomatika [KOMPUTA].2(1). 36-37.

[3] Rasidi, Didi. 2011. Institut Pemerintahan dalam Negeri : Monitoring dan Evaluasi.http://perencanaan.ipdn.ac.id/kajianperencanaan/kajian-perencanaan/monitoringdanevaluasi. Tanggal akses 29 Januari 2015.

[4] Jogianto. 2005. Analisis dan Desain Sistem Informasi. Penerbit Andi. Yogyakarta. 